\title{
Correction to: Catalytic Processes for Biomass-Derived Platform Molecules Valorisation
}

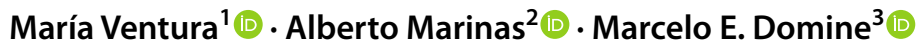

Published online: 20 April 2021

○) Springer Science+Business Media, LLC, part of Springer Nature 2021

\section{Correction to: Topics in Catalysis (2020) 63:846-865 https://doi.org/10.1007/s11244-020-01309-9}

The original version of this article unfortunately contained an error. The authors would like to correct the error with this erratum. The correct Acknowledgement and Funding information are as follow:

MED acknowledges financial support by the Spanish Government (PGC2018-097277-B-I00 and SEV-2016-0683) and Generalitat Valenciana (GVA, PROMETEO/2018/006). AMA is thankful to MINECO financial support (ENE201681013-R (AEI / FEDER, UE) and Andalusian Government (UCO-FEDER Project CATOLIVAL, re. 1264113-R, 2018 call).
Publisher's Note Springer Nature remains neutral with regard to jurisdictional claims in published maps and institutional affiliations.

The original article can be found online at https://doi.org/10.1007/ s11244-020-01309-9.

Marcelo E. Domine

mdomine@itq.upv.es

1 Department of Chemical and Environmental Technology,

ESCET, Universidad Rey Juan Carlos, Móstoles,

28933 Madrid, Spain

2 Organic Chemistry Department, Universidad de Córdoba, Campus de Rabanales, Marie Curie Building, 14014 Córdoba, Spain

3 Instituto de Tecnología Química, ITQ (UPV-CSIC), Universitat Politècnica de València, Consejo Superior de Investigaciones Científicas, Avda. Los Naranjos S/N, Valencia, Spain 